\title{
Percutaneous cholecystostomy for delayed laparoscopic cholecystectomy in patients with acute cholecystitis: analysis of a single-centre experience and literature review
}

\author{
Erdinc Kamer ${ }^{1}$, Fevzi Cengiz ${ }^{1}$, Volkan Cakir ${ }^{2}$, Omur Balli², Turan Acar ${ }^{1}$, Mustafa Peskersoy ${ }^{1}$, Mehmet Haciyanli ${ }^{1}$ \\ ${ }^{1}$ Department of Surgery, Ataturk Training and Research Hospital, Izmir Katip Celebi University, Izmir, Turkey \\ ${ }^{2}$ Department of Interventional Radiology, Ataturk Training and Research Hospital, Izmir Katip Celebi University, Izmir, Turkey
}

Gastroenterology Rev 2017; 12 (4): 250-255

DOI: https://doi.org/10.5114/pg.2017.72098

Key words: cholecystitis, calculous, cholecystostomy, percutaneous.

Address for correspondence: Assoc. Prof. Erdinc Kamer, Department of Surgery, Ataturk Training and Research Hospital, Izmir Katip Celebi University, 35540 Izmir, Turkey, phone: +90 232 2444444/2546, e-mail: erdinc.kamer@gmail.com

\begin{abstract}
Introduction: Percutaneous cholecystostomy (PC) has been used as a relatively safe and efficient temporising measure in the treatment of acute cholecystitis (AC) in high-risk patients with serious co-morbidity and in elderly patients.

Aim: To assess the effectiveness, possible advantages, and complication of delayed laparoscopic cholecystectomy (LC) following PC in patients with $A C$.

Material and methods: A total of 52 LC for AC were divided into two groups: the first group consisted of patients who had PC followed by LC (PCLC group, $n=12$ ), and the second group consisted of patients who had conservative treatment followed by LC (non-PCLC group, $n=40$ ). Eight of these patients were males and four were female. The groups were statistically compared regarding their demographic, comorbidity, hospital stay, conservation, and complication rates. PC was performed via the transhepatic route under ultrasound guidance using local anaesthesia.

Results: Percutaneous cholecystostomy was technically successful in 12 patients with no attributable mortality or major complications. Upon the regression of cholecystitis and the decrease in APACHE-II scores, the PC catheter was unplugged and elective LC was scheduled for after 8 weeks. Ninety-two percent had complete resolution of symptoms within $48 \mathrm{~h}$ of intervention while $8 \%$ had partial resolution. All of the patients in PCLC and non-PCLC groups recovered well from cholecystectomy.

Conclusions: This study suggests that PCLC would not significantly improve the outcome of LC as assessed by conversion and morbidity rate and hospital stay compared with non-PCLC. Percutaneous cholecystostomy is a valid alternative for patients with acute cholecystitis. And our study shows that the laparoscopic cholecystectomy is a good option in high-risk patients who have been treated by percutaneous cholecystostomy for acute cholecystitis.
\end{abstract}

\section{Introduction}

One of the most frequent emergency admissions to general surgical services is acute cholecystitis (AC). Emergency cholecystectomy, delayed or interval laparoscopic cholecystectomy $(\mathrm{LC})$ after medical treatment for AC is associated with high morbidity and mortality rates in patients with significant comorbidities and high-risk surgery [1, 2]. In patients with AC, percutaneous cholecystostomy (PC) has been advocated by many authors to be preferable to surgery, but no consensus has been reached on the need for subsequent cholecystectomy [1].
Surgical cholecystostomy, introduced by Bobbs, was the only available treatment of AC for more than a century. Percutaneous cholecystostomy was first described in 1921 as a diagnostic test. US-guided cholecystostomy for therapeutic purposes was first reported in 1979 [1]. The first report of PC for the management of acute cholangitis was in 1980. It has been used as a relatively safe and efficient temporising measure in the treatment of acute cholecystitis in high-risk patients with serious co-morbidity and in elderly patients, circumventing the general anaesthesia required for laparoscopic or open cholecystectomy [2, 3]. 

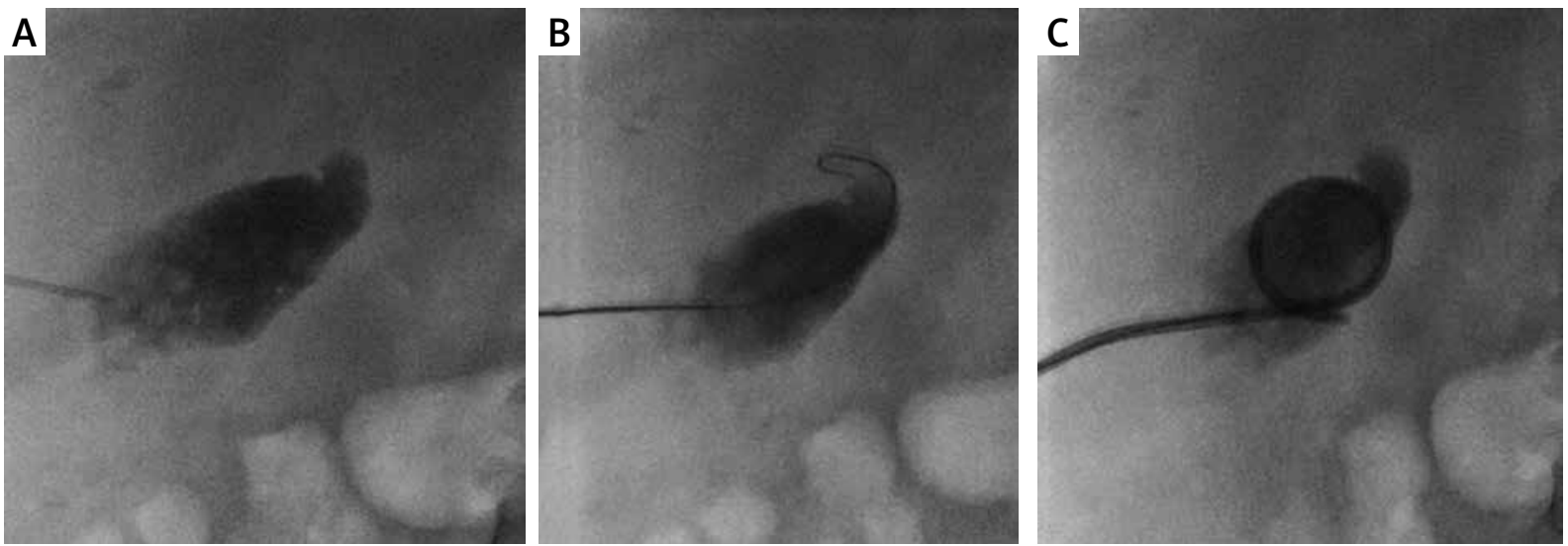

Figure 1. Fluoroscopic images showed contrast injection in the gallbladder and filling defects which were consistent with stones and biliary sludge (A), wire (B), and locking pig tail after placed in the gallbladder (C)

\section{Aim}

The purpose of this study was to assess the effectiveness, possible advantages, and complication of delayed LC following PC in patients with AC.

\section{Material and methods \\ Study group}

Between December 2014 and December 2015 , 52 patients underwent LC for clinical AC in our hospital. Of these, 12 high-risk patients were treated by percutaneous cholecystostomy for acute cholecystitis before LC.

The review board of our hospital approved the study protocol.

A total of $52 \mathrm{LC}$ for AC were divided into two groups: the first group consisted of patients who had PC followed by LC (PCLC group, $n=12$ ), and the second group consisted of patients who had conservative treatment followed by LC (non-PCLC group, $n=40$ ). The groups were statistically compared regarding their demographic, comorbidity, hospital stay, American Society of Anaesthesiologists (ASA) classification, conservation, and complication rates.

The diagnosis of acute cholecystitis was established by clinical data (history and physical examination), laboratory data (elevated leukocyte and C-reactive protein), and ultrasonographic findings (a thickened gallbladder wall and presence of concernments or sludge in the gallbladder). All patients were treated according to prospective guidelines, which included initial treatment with antibiotics, bowel rest, intravenous fluids, and analgesics. Antibiotics were used in all patients and included a combination of ampicillin and an aminoglycoside. Metronidazole was added in elderly patients and in diabetics to cover potential anaerobes.

We included 12 consecutive patients treated with PC for acute AC in high-risk patients with serious co-morbidity.
Twelve patients had PC tubes placed. Eight of these patients were males and 4 were female. All patients had AC and calculous cholecystitis. All patients were ASA III/IV.

\section{Technique of percutaneous cholecystostomy}

Percutaneous cholecystostomy was performed via the transhepatic route under ultrasound guidance using local anaesthesia. A pigtail catheter, $8 \mathrm{Fr}$ in size, was introduced into the gallbladder using the Seldinger technique (Figures 1, 2). A sample of bile was aspirated and sent for culture. The same specialised interventional radiologist team (VC and $\mathrm{OB}$ ) performed all procedures.

\section{Operative technique}

In the absence of symptoms related to a complication, under general anaesthesia, the four-cannula tech-

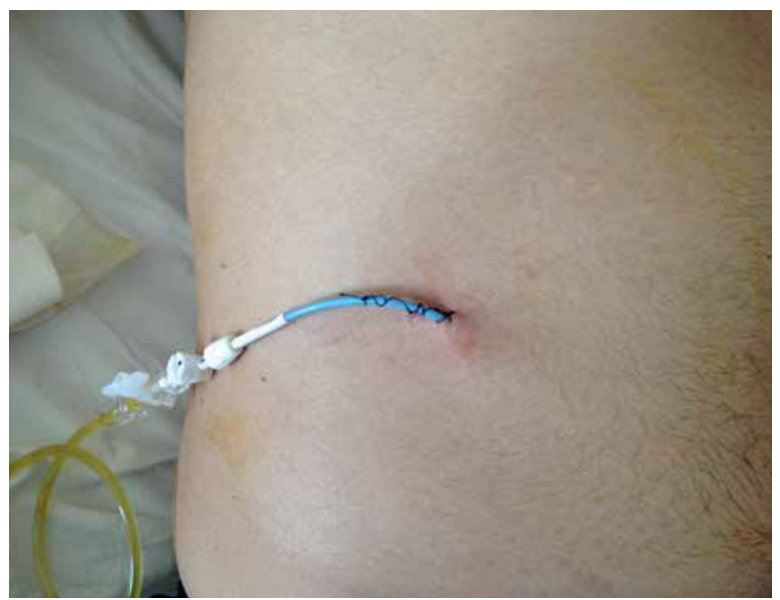

Figure 2. External appearance after percutaneous cholecystostomy 
nique of LC was attempted in all cases. All of the PCLC group had delayed LC.

\section{Statistical analysis}

Student's $t$ test or Pearson's $\chi^{2}$ and Fisher's exact test were used for the comparisons of the two groups. The results were expressed as mean \pm SD. A $p$-value of $<0.05$ was regarded as indicating a significant difference.

\section{Results}

All patients were considered to be at extremely high anaesthetic or surgical risk because many of these patients had underlying comorbid disease, as shown in Tables I, II. Percutaneous cholecystostomy was technically successful in 12 patients with no attributable mortality or major complications. Median duration of symptoms on presentation was 3.1 days (range: 1-6 days). All patients received antibiotics in addition to PC. Median interval from admission to PC was 2.1 day. Bile aspirated at the time tube placement was culture positive in $8(67 \%)$ patients. Escherichia coli were the most frequently cultured pathogen (40\%). Three patients developed non-drain-related complications; transient ileus $(n=1)$, atrial fibrillation $(n=1)$, and pneumonia $(n=1)$.

Upon the regression of cholecystitis and the decrease in APACHE II scores, the PC catheter was unplugged and elective LC was scheduled for after 8 weeks. "Ninety-two percent had complete relief of symptoms within $48 \mathrm{~h}$ of intervention while $8 \%$ had par- tial relief of symptoms". All of the patients in PCLC and non-PCLC groups recovered well from cholecystectomy. In the non-PCLC group, 13 had early LC and 27 had delayed LC after a median of 73 days (range: 48-96) of admission because of delayed transfer from internal medicine after control of comorbidity. We defined early LC as operation within $72 \mathrm{~h}$ of admission and delayed LC as after $72 \mathrm{~h}$ of admission. The PCLC group included a large percentage of patients with combined medical disease when compared with the non-PCLC group. Post-LC complications occurred in $3(25 \%)$ and 7 (17.5\%) cases (PCLC and non-PCLC, respectively). Complications occurred in wound infection $(n=1)$ and pulmonary problems $(n=2)$ in the PCLC group and wound infections $(n=2)$, pulmonary problems $(n=3)$, and urinary problem $(n=2)$ in the nonPCLC group, but mortality was nil. Median LC time was 108 min (range: 45-115) in the PCLC group. It was longer than those of the non-PCLG early LC group (median: 92 min, range: 35-145) and non-PCLC group delayed LC group (83 min, range: 37-116). The conversion rate of the PCLC group was $16.6 \%$. The mean hospital stay was $10.4 \pm 2.3$ (range: 4-16) days in the PC groups and $16.3 \pm 1.8$ (range: $9-23$ ) days in the non-PCLC group $(p=0.001)$ (Table II). No perioperative and postoperative mortality was seen in the PCLC group or the nonPCLC group.

\section{Discussion}

Acute cholecystitis is a common disease with an incidence of $1-3 \%$ per year in patients with gallstones

Table I. Patients characteristics

\begin{tabular}{|c|c|c|c|c|c|c|c|c|c|c|}
\hline No. & Age & Sex & AC aetiology & US finding & Comorbidity & $a$ & b & C & $\begin{array}{c}\text { PC unplugged } \\
\text { [day }]\end{array}$ & $\begin{array}{c}\text { Timing of LC } \\
\text { [day] }\end{array}$ \\
\hline 1 & 29 & $M$ & Stone & $A C$ & $\mathrm{TM}+\mathrm{HT}$ & III & 1 & 12 & 21 & 68 \\
\hline 2 & 65 & M & Stone & $A C$ & $\mathrm{DM}, \mathrm{CAD}$ & III & 3 & 3 & 19 & 63 \\
\hline 3 & 66 & M & Stone & $A C$ & CRF, DM, CAD, HT & IV & 2 & 6 & 21 & 72 \\
\hline 4 & 76 & $\mathrm{~F}$ & Stone & $A C$ & $C A D, C F$ & III & 2 & 8 & 20 & 62 \\
\hline 5 & 39 & $\mathrm{~F}$ & Stone & $A C$ & CAD, DM & III & 4 & 10 & 21 & 60 \\
\hline 6 & 61 & F & Stone & $A C$ & DM, HT & IV & 2 & 10 & 24 & 85 \\
\hline 7 & 77 & M & Stone & $A C$ & CAD, MI & III & 1 & 12 & 19 & 56 \\
\hline 8 & 54 & F & Stone & $A C$ & $\mathrm{DM}, \mathrm{KY}$ & IV & 1 & 10 & 20 & 58 \\
\hline 9 & 61 & M & Stone & $A C$ & $\mathrm{DM}, \mathrm{HT}, \mathrm{CAD}$ & IV & 2 & 5 & 20 & 66 \\
\hline 10 & 69 & M & Stone & $A C$ & COPD & III & 2 & 11 & 22 & 70 \\
\hline 11 & 70 & M & Stone & $A C$ & DM, HT, COPD & IV & 2 & 20 & 24 & 70 \\
\hline 12 & 62 & M & Stone & $A C$ & HT & III & 3 & 16 & 20 & 63 \\
\hline
\end{tabular}

a-ASA score, $b$ - time from PC placement to LC (day), c - hospital length of stay (day), US - ultrasonography, CRF - chronic renal failure, CAD - coronary artery disease, COPD - chronic obstructive pulmonary disease, HT-hypertension, MI-myocardial infarction, CF-cardiac failure, DM - diabetes mellitus, AC - acute cholecystitis, TM - thalassemia minor, LC - laparoscopic cholecystectomy. 
Table II. Clinical data

\begin{tabular}{|c|c|c|c|}
\hline Parameter & PCLC group $(n=12)$ & Non-PCLC group $(n=40)$ & $P$-value \\
\hline Age $^{\mathrm{a}}$, median (range) [years] & $60.8(29-77)$ & $62.7(27-82)$ & 0.56 \\
\hline Gender $^{b}$, male/female & $8 / 4$ & $32 / 8$ & 1.15 \\
\hline $\mathrm{BMI}^{\mathrm{a}}$, mean $\pm \mathrm{SD}\left[\mathrm{kg} / \mathrm{m}^{2}\right]$ & $22.7 \pm 2.2$ & $20.3 \pm 1.5$ & 1.00 \\
\hline Combined medical disease: & 25 & 31 & 1.00 \\
\hline Diabetes mellitus & 7 & 12 & \\
\hline Coronary artery disease & 6 & 5 & \\
\hline Hypertension & 6 & 14 & \\
\hline COPD & 2 & - & \\
\hline Chronic renal failure & 1 & - & \\
\hline Myocardial infarction & 1 & 1 & \\
\hline Cardiac failure & 1 & - & \\
\hline Thalassemia minor & 1 & - & \\
\hline \multicolumn{4}{|l|}{ ASA grades, $n(\%)$} \\
\hline $1 \mathrm{II}^{\mathrm{b}}$ & $7(58.3)$ & $17(42.5)$ & 0.03 \\
\hline $\mathrm{IV}$ & $5(41.7)$ & $5(12.5)$ & 0.04 \\
\hline LC time, median (range) [min] & $108(45-115)$ & $87.5(35-145)$ & 0.001 \\
\hline Complication, $n$ (\%) & $3(25)$ & $7(17.5)$ & 0.63 \\
\hline Total hospital stay, median [day] & $10.4 \pm 2.3$ & $16.3 \pm 1.8$ & 0.001 \\
\hline Conversion rate ${ }^{\mathrm{b}}(\%)$ & 2/12 (16.6) & $2 / 40(5)$ & 0.01 \\
\hline
\end{tabular}

(10-20\%) [1, 2]. Acute cholecystitis carries a risk of complications including empyema, gangrene, perforation, and peritonitis. Cholecystectomy is the treatment of choice either open or laparoscopic. Nevertheless, two persistent issues remain: a high rate of conversion and the management of critically ill patients who are not good candidates for general anaesthesia. Also, the morbidity and mortality associated with emergent cholecystectomy is considerably high in critically ill patients: $55-66 \%$ and $14-30 \%$, respectively [3].

Surgical cholecystostomy followed by delayed LC has been proposed for the management of these patients as an alternative treatment [3]. In recent years, ultrasound-guided PC followed by delayed LC has become an alternative to surgical cholecystostomy for AC in patients at high surgical risk [2]. Percutaneous cholecystostomy has been developed as a less invasive procedure compared to open cholecystectomy in critically ill patients with AC. The technical success of PC can be very high in experienced hands, with reported rates of $95-100 \%$ [4]. Learning curve of the performing team can decrease these rates. The $100 \%$ technical success in our series is comparable with these rates [2, 4]. Mortality related to $\mathrm{PC}$ has a prevalence of $0-3 \%$, whereas minor post-PC complications have been mentioned in $4-18 \%$ of cases. Bile leakage is the most common complications which may lead to life-threatening peritonitis [4].

It is a rather uncomplicated procedure with a low complication rate that is reported to range from 3 to $13 \%$ [5]. Percutaneous cholecystostomy was technically successful in all patients with no attributable mortality or major complications (such as bleeding, bile leak, sepsis following a pulled catheter, peritonitis, or shock) in this current study. In an effort to extend the benefits of PC and LC, we developed an alternative management approach for high-risk patients with AC. The patients were treated with PC for early decompression of gallbladder, followed by an early LC [6]. Akyürek et al. compared early PC followed by early cholecystectomy against medical treatment and delayed cholecystectomy in 70 high-risk patients (ASA grade II-IV), concluding that the PC and early cholecystectomy group benefit- 
Table III. Review of the literature

\begin{tabular}{lcccccccc} 
Authors (references) & $\begin{array}{c}\text { Year of } \\
\text { publication }\end{array}$ & $\boldsymbol{N}$ & $\begin{array}{c}\text { Mean age } \\
\text { [years] }\end{array}$ & $\begin{array}{c}\text { Calculous/ } \\
\text { acalculous }\end{array}$ & $\begin{array}{c}\text { PC success } \\
\text { (\%) }\end{array}$ & $\begin{array}{c}\text { Mortality } \\
\text { (\%) }\end{array}$ & $\begin{array}{c}\text { Morbidity } \\
\text { (\%) }\end{array}$ & EC (\%) \\
\hline Patel et al. [10] & 2000 & 53 & 63 & $39 / 14$ & 83 & 17 & $?$ & 47.2 \\
\hline Granlund et al. [11] & 2001 & 51 & 71 & $28 / 23$ & 90 & 16 & 4 & 2 \\
\hline Hatzidakis et al. [4] & 2002 & 63 & 79 & $44 / 19$ & 86 & 17.5 & $?$ & 11 \\
\hline Spira et al. [12] & 2002 & 55 & 74 & $?$ & 98 & 5.5 & 1.8 & 4 \\
\hline Byrne et al. [13] & 2003 & 45 & 63 & $?$ & 78 & 22.2 & 15.6 & 0 \\
\hline Li et al. [14] & 2004 & 25 & 81 & $?$ & 92 & 20 & 12 & 8 \\
\hline Welschbillig-Meunier et al. [15] & 2005 & 65 & 78 & $49 / 16$ & 90 & 13.8 & 12.3 & 3 \\
\hline Ha et al. [16] & 2008 & 65 & 63 & $65 / 0$ & 91 & 12.3 & $?$ & $?$ \\
\hline Melloul et al. [5] & 2010 & 23 & 65 & $11 / 12$ & 91 & 13 & 0 & 8.7 \\
\hline Kortram et al. [9] & 2011 & 27 & 83 & $27 / 0$ & 92.6 & 14.8 & 25.9 & 14.8 \\
\hline Chung et al. [1] & 2012 & 57 & 71 & $0 / 57$ & 100 & 0 & 0 & 31.0 \\
\hline Sanjay et al. [17] & 2013 & 53 & 74 & $33 / 20$ & 100 & 7 & 18 & 33 \\
\hline Zerem et al. [18] & 2014 & 36 & 75 & $32 / 4$ & 100 & 2.8 & 41.7 & 16.7 \\
\hline Viste et al. [19] & 2015 & 104 & 73.5 & $86 / 18$ & 100 & 3.8 & 12.5 & 18.3 \\
\hline Present study & 2015 & 12 & 60.8 & $12 / 0$ & 100 & 0 & 25 & 100
\end{tabular}

$P C$ - percutaneous cholecystostomy, EC - elective cholecystectomy.

ed from significantly shorter hospital stay and time to symptomatic improvement. There was no significant difference in postoperative complications between the groups [6]. The $27.3 \%$ morbidity rate and no mortality in the current study was comparable with morbidity rates of $3 \%$ to $4 \%$ and mortality rates of $0.4 \%$ to $3.1 \%$ in the literature [7]. Three patients developed non-drain-related complications. The safety of PC is well demonstrated in published studies and in our study (Table III).

So far, there are only two published randomised studies related to PC in calculous cholecystitis. Hatzidakis et al. found no difference in complications following $P C$ and antibiotics versus conservative treatment only, whereas Akyürek et al. concluded that PC and early laparoscopic cholecystectomy was favourable compared to PC and LC later on $[4,6]$. In a review including those randomised trials Gurusamy et al. concluded that so far there is no hard evidence concerning the benefit of $P C$ in acute cholecystitis [8]. The results following the Dutch "Chocolate study" randomising between PC and LC in severely morbid patients will hopefully solve some of these issues [9].

\section{Conclusions}

The results of this study suggest that PCLC would not significantly improve the outcome of LC as assessed by conversion and morbidity rate and hospital stay compared with non-PCLC. Percutaneous cholecystostomy has a role in the definitive management of high-risk group patients with acute cholecystitis. It is convenient, has a relatively low and acceptable complication rate, and is rapidly effective. Interval laparoscopic cholecystectomy can be safety performed. Percutaneous cholecystostomy is a valid alternative for patients with acute cholecystitis. Our study shows that the laparoscopic cholecystectomy is a good option in high-risk patients wo have been treated by percutaneous cholecystostomy for AC.

\section{Conflict of interest}

The authors declare no conflict of interest.

\section{References}

1. Chung YH, Choi ER, Kim KM, et al. Can percutaneous cholecystostomy be a definitive management for acute acalculous cholecystitis? J Clin Gastroenterol 2012; 46: 216-9.

2. Peters R, Kolderman S, Peters B, et al. Percutaneous cholecystostomy: single centre experience in 111 patients with an acute cholecystitis. JBR-BTR 2014; 97: 197-201.

3. Nasim S, Khan S, Alvi R, et al. Emerging indications for percutaneous cholecystostomy for the management of acute cholecystitis. A retrospective review. Int J Surg 2011; 9: 456-9. 
4. Hatzidakis AA, Prassopoulos P, Petinarakis I, et al. Acute cholecystitis in high-risk patients: percutaneous cholecystostomy vs conservative treatment. Eur Radiol 2002; 12: 1778-84.

5. Melloul E, Denys A, Demartines N, et al. Percutaneous drainage versus emergency cholecystectomy for the treatment of acute cholecystitis in critically ill patients: does it matter? World J Surg 2011; 35: 826-33.

6. Akyürek N, Salman B, Yüksel O, et al. Management of acute calculous cholecystitis in high-risk patients: percutaneous cholecystotomy followed by early laparoscopic cholecystectomy. Surg Laparosc Endosc Percutan Tech 2005; 15: 315-20.

7. Kim KH, Sung CK, Park BK, et al. Percutaneous gallbladder drainage for delayed laparoscopic cholecystectomy in patients with acute cholecystitis. Am J Surg 2000; 179: 111-3.

8. Gurusamy KS, Rossi M, Davidson BR. Percutaneous cholecystostomy for high-risk surgical patients with acute calculous cholecystitis. Cochrane Database Syst Rev 2013; 8: CD007088.

9. Kortram K, van Ramshorst B, Bollen TL, et al. Acute cholecystitis in high risk surgical patients: percutaneous cholecystostomy versus laparoscopic cholecystectomy (CHOCOLATE trial): study protocol for a randomized controlled trial. Trials 2012; 13: 7.

10. Patel M, Miedema BW, James MA, et al. Percutaneous cholecystostomy is an effective treatment for high-risk patients with acute cholecystitis. Am Surg 2000; 66: 33-7.

11. Granlund A, Karlson BM, Elvin A, et al. Ultrasound-guided percutaneous cholecystostomy in high-risk surgical patients. Langenbecks Arch Surg 2001; 386: 212-7.

12. Spira RM, Nissan A, Zamir O, et al. Percutaneous transhepatic cholecystostomy and delayed laparoscopic cholecystectomy in critically ill patients with acute calculus cholecystitis. Am J Surg 2002; 183: 62-6.

13. Byrne MF, Suhocki P, Mitchell RM, et al. Percutaneous cholecystostomy in patients with acute cholecystitis: experience of 45 patients at a US referral center. J Am Coll Surg 2003; 197: 206-11.

14. Li JC, Lee DW, Lai CW, et al. Percutaneous cholecystostomy for the treatment of acute cholecystitis in the critically ill and elderly. Hong Kong Med J 2004; 10: 389-93.

15. Welschbillig-Meunier K, Pessaux P, Lebigot J, et al. Percutaneous cholecystostomy for high-risk patients with acute cholecystitis. Surg Endosc 2005; 19: 1256-9.

16. Ha JP, Tsui KK, Tang CN, et al. Cholecystectomy or not after percutaneous cholecystostomy for acute calculous cholecystitis in high-risk patients. Hepatogastroenterology 2008; 55 : 1497-502.

17. Sanjay P, Mittapalli D, Marioud A, et al. Clinical outcomes of a percutaneous cholecystostomy for acute cholecystitis: a multicentre analysis. HPB (Oxford) 2013; 15: 511-6.

18. Zerem E, Omerović S. Can percutaneous cholecystostomy be a definitive management for acute cholecystitis in high-risk patients? Surg Laparosc Endosc Percutan Tech 2014; 24: 187-91.

19. Viste A, Jensen D, Angelsen J, et al. Percutaneous cholecystostomy in acute cholecystitis; a retrospective analysis of a large series of 104 patients. BMC Surg 2015; 8: 15-7.

Received: 5.04.2016

Accepted: 17.08 .2016 